\title{
Adsorption of Bismarck Brown R Dye Onto Multiwall Carbon Nanotubes
}

\section{Ahmed M. Kamil, Firas H. Abdalrazak, Ahmed F. Halbus and Falah H. Hussein*}

Department of Chemistry, College of Science, Babylon University, Hilla, Iraq

\begin{abstract}
In this work, Multiwall carbon nanotubes (MWCNTs) were used in the adsorptive removal of Bismarck Brown $\mathrm{R}$ (BBR) dye from an aqueous solution. The effects of contact time, MWCNT dosage, dye concentration, pH and temperature on adsorption of BBR dye by MWCNTs were investigated. The adsorption study was analyzed kinetically, and the results revealed that the adsorption followed pseudo-second order kinetics with good correlation coefficients.

The equilibrium adsorption data was analyzed using three common adsorption models: Langmuir, Freundlich and Temkin. Gibbs free energy change values showed that the adsorptions of BBR dye on MWCNTs is spontaneous. The results also indicate that the adsorption is physisorption.
\end{abstract}

Keywords: Adsorption; MWCNTs; Bismarck brown R; Kinetics, Isotherms

\section{Introduction}

Dyes have long been used in different types of industries such as, dyeing, textiles, paper, plastics, leather and cosmetics [1]. Color stuff discharged from these industries pose hazards and has an environmental impact [2].The presences of dyes in water are causing problems, such as, reducing oxygen levels in water; interfering with penetration of sunlight into waters; retarding photosynthesis and interfering with gas solubility in water bodies [3].

Azo dyes are divided according to the presence of azo bonds ($\mathrm{N}=\mathrm{N}-$ ) in the molecule; these include mono azo, diazo, triazoetc [4]. Azo dyes resist the effect of oxidation agents and light, thus they cannot be completely treated by conventional methods of anaerobic digestion [5]. It is necessary to find an effective method for the treatment of Bismarck Brown R. The degradation of Bismarck brown R dye in the presence of aqueous zinc oxide suspension has been reported before [6]. The adsorption technique proved to be an effective and attractive process for removing dyes from aqueous solutions in term of initial cost, ease of operation, insensitivity to toxic substance, high efficiency, easy recovery and simplicity of design $[7,8]$. Carbon nanotubes (CNTs) are relatively new adsorbents that can absorb organic pollutants from wastewater $[9,10]$. CNTs were discovered in 1991 as a minor byproduct of fullerene synthesis. CNTs are made up of concentric rolled graphene sheets. CNTs include single wall (SWCNTs) and multiwall (MWCNTs) depending on the number of sheets comprising them [11]. They have many applications because of their various properties such as high thermal and electrical conductivities, strength, mechanical and special adsorption properties [12].

In this work, commercial MWCNTs were used as an adsorbent to remove Bismarck Brown $\mathrm{R}$ from aqueous solution. The main objective of this research was to evaluate the adsorption ability of carbon nanotubes for the removal of Bismarck Brown $\mathrm{R}$ as a model compound for basic dyes. The effects of contact time, MWCNTs dosage, initial dye concentration, $\mathrm{pH}$ and temperature on adsorption capacity were studied. Kinetic and equilibrium models were used to fit experimental data and the adsorption thermodynamic parameters.

\section{Experimental}

\section{Materials and methods}

Adsorbent: Multiwall carbon nanotubes (MWCNTs) with diameter of $20-30 \mathrm{~nm}$ and length of $10-30 \mu \mathrm{m}$ was purchased from NANOSHEL.MWCNTs were used without further treatment.
Adsorbate: Bismarck Brown $\mathrm{R}$, having molecular formula $\mathrm{C}_{21} \mathrm{H}_{24} \mathrm{~N}_{8} .2 \mathrm{HCl}$ was chosen as the adsorbate. Bismarck Brown $\mathrm{R}$ was purchased from Sigma-Aldrich with water solubility as $11 \mathrm{~g} \mathrm{~L}^{-1}\left(25^{\circ} \mathrm{C}\right)$ and molecular weight as $461.39 \mathrm{~g} \mathrm{~mol}^{-1}$. The dye stock solution was prepared by dissolving Bismarck Brown $\mathrm{R}$ in distilled water to the concentration of $0.01 \mathrm{M}$. The experimental solutions were obtained by diluting the dye stock solution in accurate proportions to required initial concentrations. The IUPAC name of the Bismarck Brown $\mathrm{R}$ is 4-[5-(2, 4-Diamino-5-methylphenyl) diazenyl-2-methylphenyl] diazenyl-6-methylbenzol-1, 3-diamin. The structure of Bismarck Brown $\mathrm{R}$ is shown in figure 1 .

\section{Adsorption equilibrium experiments}

For equilibrium studies, solutions of $5 \times 10^{-5} \mathrm{M}$ Bismarck Brown $\mathrm{R}$, at the initial concentration, were treated with $25 \mathrm{mg}$ of MWCNTs. The mixtures were agitated on shakers (Gemmy orbit, van 480 Gemmy Industrial Corp-Taiwan) continuously for $60 \mathrm{~min}$, as the equilibrium time, at different temperature and $\mathrm{pH}$. All adsorption experiments were done in dark to avoid illuminations effects [13]. After $60 \mathrm{~min}$, the suspensions were filtered using a centrifuge and the filtrates were analyzed for residual Bismarck Brown R concentration by UVvisible spectrophotometer (PG instruments Ltd- Japan) at $459 \mathrm{~nm}$. The amount of Bismarck Brown R uptake by CNTs in each flask was calculated using the mass balance equation:

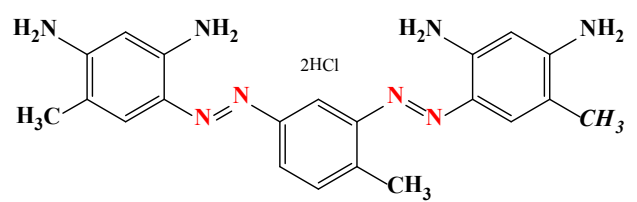

Figure 1: Chemical structure of Bismarck Brown $\mathrm{R}$.

*Corresponding author: Falah H. Hussein, Department of Chemistry, College of Science, Babylon University, Hilla, Iraq, Tel: 009647804009236; E-mail: abohasan_hilla@yahoo.com

Received January 20, 2014; Accepted February 21, 2014; Published February 24,2014

Citation: Kamil AM, Abdalrazak FH, Halbus AF, Hussein FH (2014) Adsorption of Bismarck Brown R Dye Onto Multiwall Carbon Nanotubes. J Environ Anal Chem 1: 104. doi:10.4172/2380-2391.1000104

Copyright: @ 2014 Kamil AM, et al. This is an open-access article distributed under the terms of the Creative Commons Attribution License, which permits unrestricted use, distribution, and reproduction in any medium, provided the original author and source are credited. 


$$
q_{e}=\frac{\left(C_{o}-C_{e}\right)}{w} \times v
$$

Where $\mathrm{q}_{\mathrm{e}}$ is the amount of Bismarck Brown R adsorbed by CNTs at equilibrium, $\mathrm{C}_{0}$ and $\mathrm{C}_{\mathrm{e}}$ are the initial and final dye concentrations $(\mathrm{M})$, respectively, $\mathrm{V}$ is the volume of solution $(\mathrm{L})$, and $\mathrm{W}$ is the adsorbent weight (g).

The dye percent removal (\%) was calculated using the following equation:

$$
\text { Removal\% }=\frac{\left(C_{o}-C_{t}\right)}{C_{o}} \times 100
$$

\section{Adsorption kinetic experiments}

For kinetic studies, solutions of $1,3,5,7$ and $10 \times 10^{-5} \mathrm{M}$ Bismarck Brown $\mathrm{R}$, as the initial concentration, were treated with $25 \mathrm{mg}$ of MWCNTs at a constant temperature of $298.15 \mathrm{~K}$. The mixtures were then subjected to agitation using a shaker. In all cases, the working $\mathrm{pH}$ of solution was not controlled. Mixtures were taken from the shaker at appropriate time intervals $(10,20,30,40,50,60 \mathrm{~min})$ and the remaining concentration of the Bismarck Brown R solution was determined.

\section{Results and Discussion}

\section{Effect of contact time}

The effect of contact time on the adsorption capacity of Bismarck Brown R onto MWCNTs is shown in figure 2, When the initial Bismarck Brown $\mathrm{R}$ concentration is increased from $1 \times 10^{-5}$ to $10 \times 10^{-}$ ${ }^{5} \mathrm{M}$ the amount of Bismarck Brown R adsorbed onto MWCNTs, at $60 \mathrm{~min}$ contact time, $\mathrm{pH}$ value $5,25 \mathrm{mg}$ adsorbent dose and the constant temperature $298.15 \mathrm{~K}$, increased from 3.9 to $30.0 \mathrm{mg} \mathrm{g}^{-1}$. The increase of loading capacity of CNTs with increasing initial Bismarck Brown $\mathrm{R}$ concentration may be due to higher interaction between Bismarck Brown $\mathrm{R}$ and adsorbent [14]. These results show that rapid increase in adsorbed amount of Bismarck Brown $\mathrm{R}$ is achieved during the first 10 minutes. Similar results were reported before for removal of hazardous contaminants from wastewater [15].

\section{Effect of MWCNT dosage}

To determine the effect of adsorbent dosage on the adsorption of BBR, a series of adsorption experiments were carried out with different adsorbent mass at initial dye concentration of $5 \times 10^{-5} \mathrm{M}$. Figure 3 shows the effect of adsorbent dose on the removal of BBR. The increasing of adsorbent dosage from 10to50 $\mathrm{mg}$, the percentage of dye adsorbed increased from 48.61 to $98.15 \%$ after $60 \mathrm{~min}$ of adsorption time. This

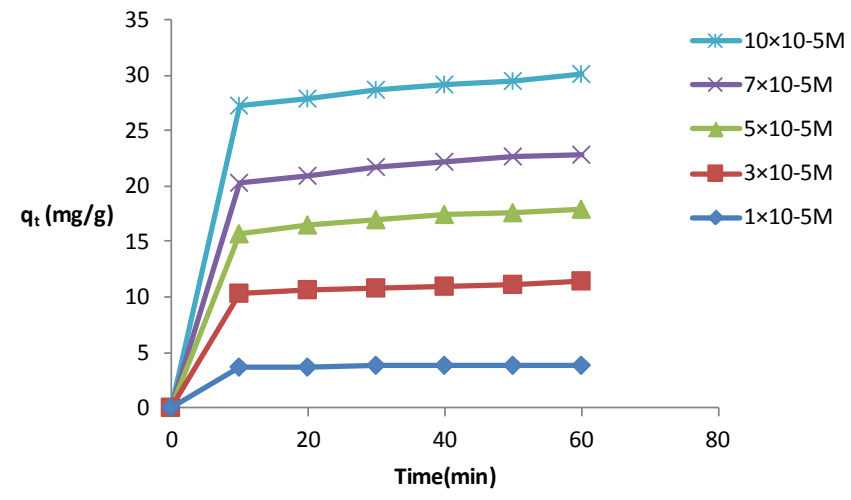

Figure 2: Effect of contact time on the adsorption of BBR dye by MWCNTs.

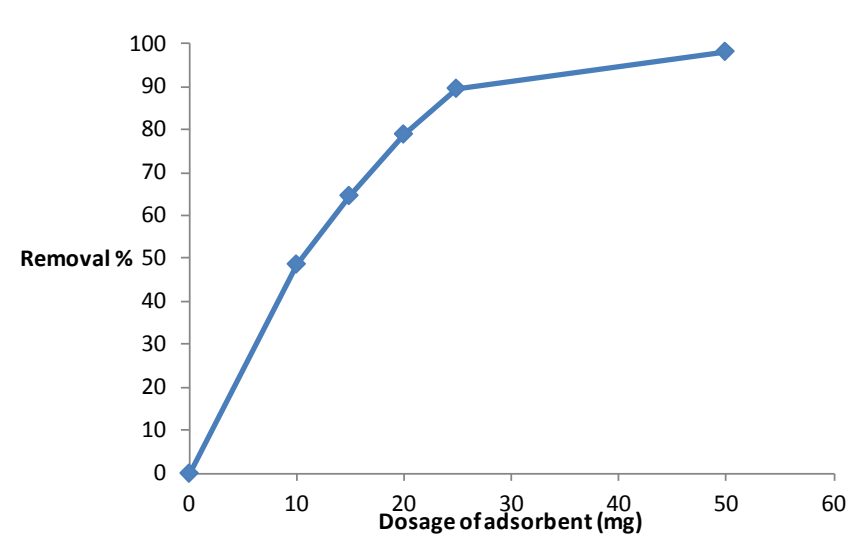

Figure 3: Effect of MWCNTs dose on the adsorption percentage of BBR.

result was expected as that the number of available adsorption sites increases by increasing the adsorbent amount [16-18].

\section{Effect of initial concentration of BBR dye}

Different concentrations of BBR1, 3, 5, 7 and $10 \times 10^{-5} \mathrm{M}$, were selected to study the effect of initial concentration of dye onto MWCNTs. The amounts of dye adsorbed at $\mathrm{pH} 5$, adsorbent dosage $25 \mathrm{mg}$ and $298.15 \mathrm{~K}$ are given in figure 4 . With increasing initial concentration of BBR from 1 to $10 \times 10^{-5} \mathrm{M}$, the removal of dye molecules decreases from 97.87 to $75.15 \%$ after $60 \mathrm{~min}$ of adsorption time. These results agree with adsorption of heavy metal ions on carbon nanotubes [19].

\section{Effect of $\mathbf{p H}$}

The $\mathrm{pH}$ of the dye solution plays an important role in the whole adsorption process, particularly on the adsorption capacity. The solution $\mathrm{pH}$ can affect the surface charge of the adsorbent and the degree of the ionization of different pollutants [20]. The effect of $\mathrm{pH}$ on the BBR dye adsorption capacities of the MWCNTs was studied at varying $\mathrm{pH}(2-10)$ with $5 \times 10^{-5} \mathrm{M}$ fixed initial dye concentration and adsorbent dosage $25 \mathrm{mg}$ for $60 \mathrm{~min}$. Figure 5 shows that the adsorption capacity of BBR dye increases with increasing the $\mathrm{pH}$ of solution from 2 to 5 and decrease slightly when solution $\mathrm{pH}$ is above 5.The maximum adsorption capacity of MWCNTs was $17.87 \mathrm{mg} / \mathrm{g}$ at $\mathrm{pH} 5$. It is well known the MWCNTs surface contains carboxylic and hydroxyl groups after purification method by acid treatment. The change in solution $\mathrm{pH}$ will effect on the ionization of these functional groups [21,22].

\section{Effect of temperature}

To study the effects of temperature on the adsorption of dye by MWCNTs, the experiments were performed at temperatures from 278.15 to 298.15 K. Figure 6 shows the influence of temperature on the adsorption of dye on MWCNTs. As it was observed, the equilibrium adsorption capacity of BBR onto MWCNTs was found to increase with increasing temperature. This fact indicates that the mobility of dye molecules increased with the temperature, additionally the viscosity of dye solution reduces with rise in temperature and as a result, it increases the rate of diffusion of dye molecules. The results were in agreement with the effect of the solution $\mathrm{pH}$, ionic strength, and temperature on adsorption behavior of reactive dyes on activated carbon [23].

\section{Adsorption isotherm}

The isotherm provides a relationship between the concentration of dye in solution and the amount of dye adsorbed on the solid phase when 


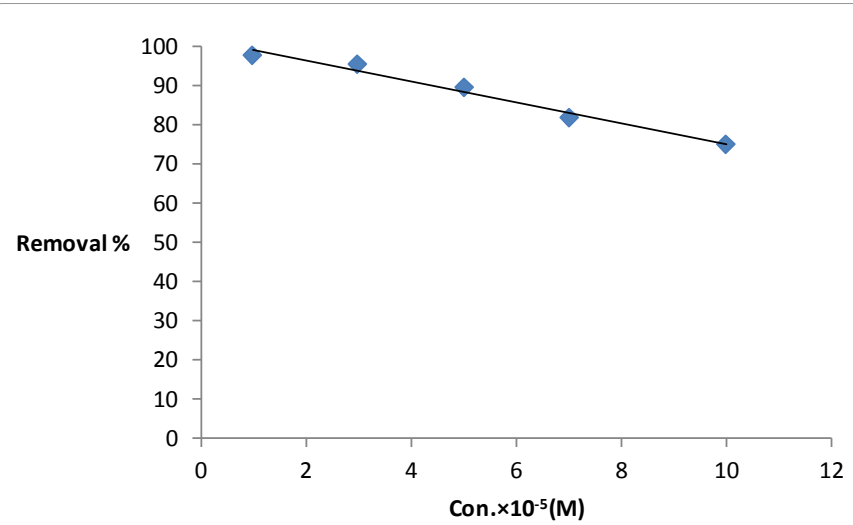

Figure 4: Effect of initial concentrations on the adsorption percentage of BBR on MWCNTs.

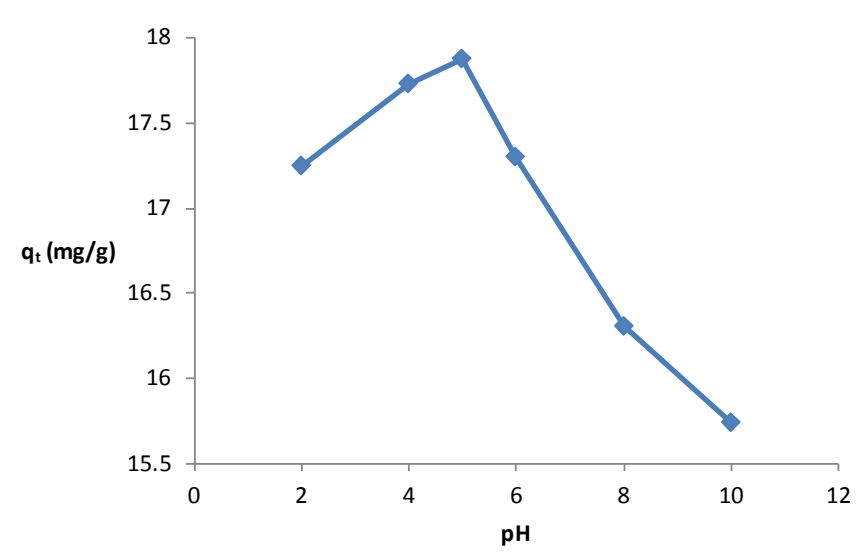

Figure 5: Effect of initial solution $\mathrm{pH}$ on the adsorption amount of BBR on MWCNTS.

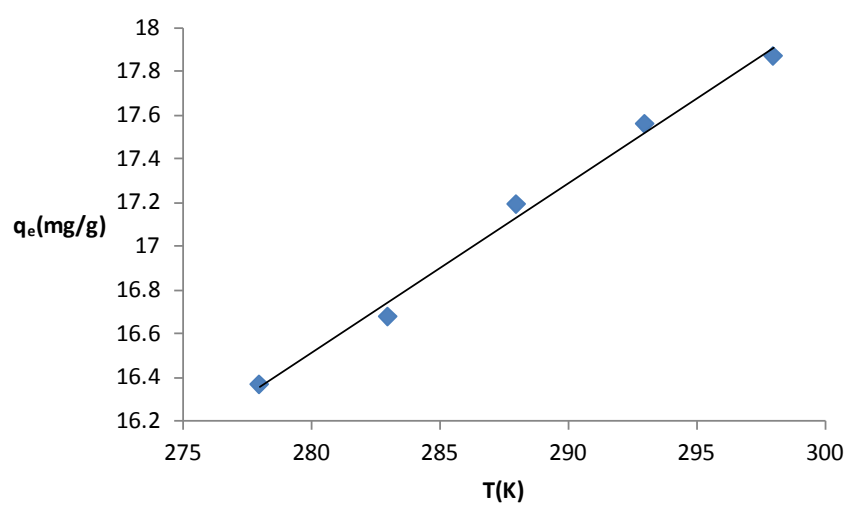

Figure 6: Effect of temperature on the adsorption amount of BBR on MWCNTs.

both phases are in equilibrium. The equilibrium of experimental data for adsorbed BBR on MWCNTs was studied by using the Langmuir, Freundlich and Temkin isotherm models. In this study, the best fit isotherm models to the experimental data were determined using the value of correlation coefficient $R^{2}$ [24].

\section{Langmuir isotherm}

The Langmuir adsorption isotherm assumes that adsorption takes place at specific homogeneous sites within the adsorbent and has found successful application in many sorption processes of monolayer adsorption [25]. Figure 7 shows the Langmuir isotherm for adsorption $\mathrm{BBR}$ on MWCNTs. The following equation is the Langmuir isotherm:

$$
q_{e}=\frac{q_{m} K_{L} C_{e}}{1+K_{L} C_{e}} \times 100
$$

Where $q_{m}$ is the maximum amount of BBR adsorbed per unit mass of MWCNTs and $\mathrm{K}_{\mathrm{L}}$ is the Langmuir constant related to rate of adsorption.

For the Langmuir equation the favorable nature of adsorption can be expressed in terms of dimensionless separation factor of equilibrium parameter $\left(\mathrm{R}_{\mathrm{L}}\right)$ [26], which is defined by:

$$
R_{L}=\frac{1}{1+K_{L} C_{\mathrm{o}}}
$$

where $\mathrm{R}_{\mathrm{L}}$ is the dimensionless equilibrium parameter and $C_{0}$ is the initial BBR concentration. The values of $R_{L}$ indicates the type of isotherm to be irreversible $\left(\mathrm{R}_{\mathrm{L}}=0\right)$, favorable $\left(0<\mathrm{R}_{\mathrm{L}}<1\right)$, linear $\left(\mathrm{R}_{\mathrm{L}}=1\right)$ or unfavorable $\left(R_{L}>1\right)$ [27]. The values of the dimensionless separation factor are given in table 1.

\section{Freundlich isotherm}

The Freundlich isotherm is an empirical equation employed to describe heterogeneous systems [28]. The Freundlich model [29] is based on the distribution of adsorbate between the adsorbent and aqueous phases at equilibrium. Figure 8 shows the Freundlich isotherm for adsorption BBR on MWCNTs. The basic Freundlich equation is:

$$
q_{e}=K_{F} C_{e}^{1 / n}
$$

where $K_{F}$ and $\mathrm{n}$ are Freundlich constants, which give a measure of adsorption capacity and adsorption intensity, respectively.

\section{Temkin isotherm}

This isotherm takes into accounts of indirect adsorbate-adsorbate interactions on adsorption isotherms and suggested that because of these interactions the heat of adsorption of all the molecules in the layer would decrease linearly with coverage [30]. Figure 9 shows the Temkin

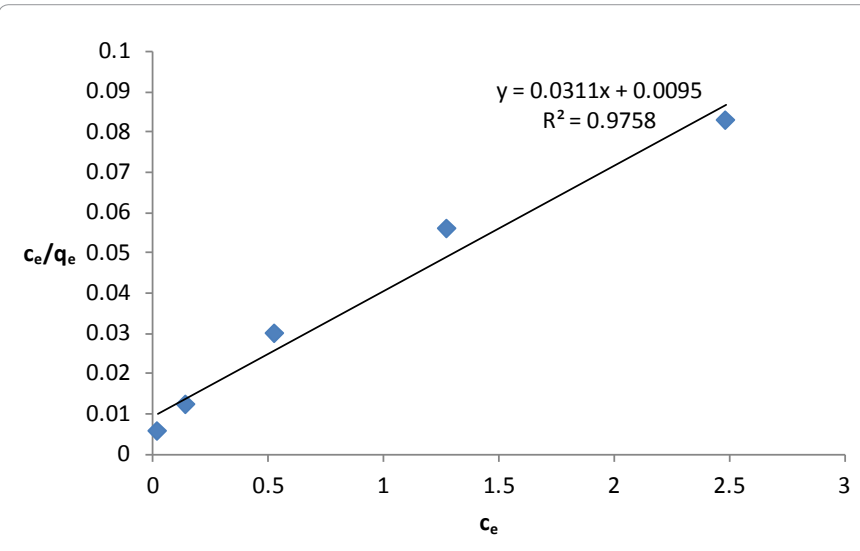

Figure 7: Langmuir isotherm for BBR adsorption onto MWCNTs.

\begin{tabular}{|c|c|}
\hline Con./M & $\mathbf{R}_{\mathbf{L}}$ \\
\hline $1 \times 10^{-5}$ & 0.9348 \\
\hline $3 \times 10^{-5}$ & 0.6827 \\
\hline $5 \times 10^{-5}$ & 0.3646 \\
\hline $7 \times 10^{-5}$ & 0.1929 \\
\hline $10 \times 10^{-5}$ & 0.1095 \\
\hline
\end{tabular}

Table 1: Dimensionless separation factor for BBR adsorption on MWCNTs. 


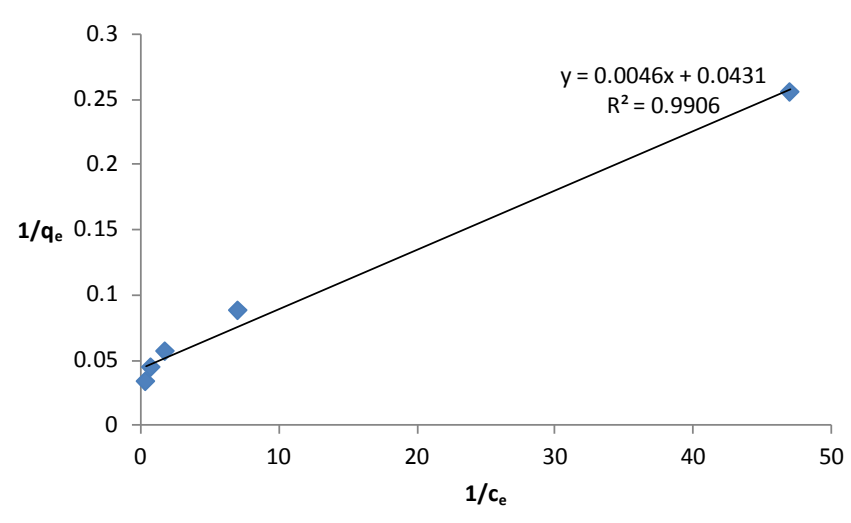

Figure 8: Freundlich isotherm for BBR adsorption onto MWCNTs.

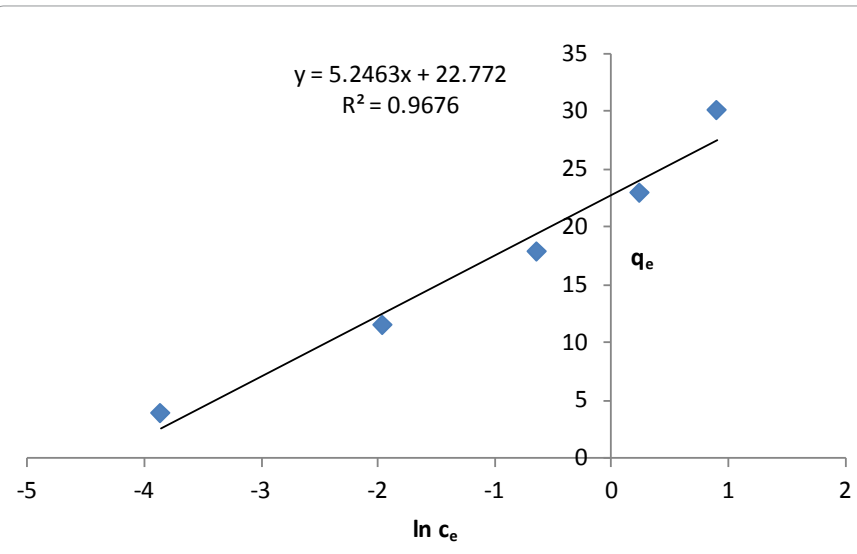

Figure 9: Temkin isotherm for BBR adsorption onto MWCNTs.

isotherm for adsorption BBR on MWCNTs. The Temkin isotherm has been used in the form given below

$$
q_{e}=B_{1} \ln C_{e}+B_{l} \ln K_{T}
$$

where $\mathrm{K}_{\mathrm{T}}$ and $\mathrm{B}_{1}$ are the Temkin constants $\left(\mathrm{K}_{\mathrm{T}}\right.$ is the equilibrium binding constant $(\mathrm{L} / \mathrm{g})$ and $\mathrm{B}_{1}$ is related to the heat of adsorption).The values of the isotherm parameters are given in table 2 .

\section{Adsorption kinetics}

Three kinetic models: Pseudo-first order, pseudo-second order and Intra particle diffusion kinetic models were used to fit experimental data to examine the adsorption kinetics. Equations 7,8 and 9 represent the linear forms of the pseudo-first order, pseudo-second order models and Intra particle diffusion kinetic model respectively

$$
\begin{aligned}
& \ln \left(q_{t}-q_{e}\right)=\ln \left(q_{e}\right)-k_{1} t \\
& \frac{t}{q_{t}}=\frac{1}{k_{2} q_{e}^{2}}+\frac{t}{q e} \\
& q_{t}=k_{3} t^{1 / 2}+C
\end{aligned}
$$

The straight-line plots of $\ln \left(\mathrm{q}_{\mathrm{e}}-\mathrm{q}_{\mathrm{t}}\right)$ versus $\mathrm{t}$ for the pseudo-first order reaction (Figure 10), $t / \mathrm{q}_{\mathrm{t}}$ versus $\mathrm{t}$ for the pseudo-second order reaction (Figure 11) and $\mathrm{q}_{\mathrm{t}}$ versus $\mathrm{t}^{1 / 2}$ for the Intra particle diffusion reaction (Figure 12) for adsorption of BBR onto MWCNTs. The values of the kinetic parameters and correlation coefficient were calculated from these plots are given in table 3 . The pseudo-second order model best represents this experimental data. Similar results have been observed before $[31,32]$.

\section{Adsorption thermodynamics}

The thermodynamic parameters, namely Gibbs free energy change $\left(\Delta \mathrm{G}^{\circ}\right)$, enthalpy change $\left(\Delta \mathrm{H}^{\circ}\right)$ and entropy change $\Delta \mathrm{S}^{\circ}$, for the adsorption processes were determined using the following equations [33-37]:

$$
\begin{aligned}
& \Delta G^{\circ}=-R T \ln K_{a d} \\
& \ln K_{a d}=\frac{\ddot{A} H^{\circ}}{R T}+\frac{\ddot{A} S^{\circ}}{R}
\end{aligned}
$$

where $\mathrm{R}$ is universal gas constant $\left(8.314 \mathrm{~J} \mathrm{~mol}^{-1} \mathrm{~K}^{-1}\right)$, and $\mathrm{T}$ is the absolute temperature in Kelvin. Thermodynamic parameters were summarized in table 4 .

The negative values of $\Delta \mathrm{G}^{\circ}$ indicate that the adsorption process

\begin{tabular}{|c|c|c|}
\hline Isotherm & Parameters & Values \\
\hline \multirow{3}{*}{ Langmuir } & $Q_{m}$ & 32.15 \\
\hline & $\mathrm{K}_{\mathrm{L}}$ & 3.27 \\
\hline & $\mathrm{R}^{2}$ & 0.9758 \\
\hline \multirow{3}{*}{ Freundlich } & $\mathrm{K}_{\mathrm{F}}$ & 3.81 \\
\hline & $n$ & 2.39 \\
\hline & $\mathrm{R}^{2}$ & 0.9799 \\
\hline \multirow{3}{*}{ Temkin } & $\mathrm{B}_{1}$ & 5.24 \\
\hline & $\mathrm{K}_{\mathrm{T}}$ & 76.75 \\
\hline & $\mathrm{R}^{2}$ & 0.9676 \\
\hline Isotherm & Parameters & Values \\
\hline \multirow{3}{*}{ Langmuir } & $Q_{m}$ & 32.15 \\
\hline & $\mathrm{K}_{\mathrm{L}}$ & 3.27 \\
\hline & $\mathrm{R}^{2}$ & 0.9758 \\
\hline \multirow{3}{*}{ Freundlich } & $\mathrm{K}_{\mathrm{F}}$ & 3.81 \\
\hline & $\mathrm{n}$ & 2.39 \\
\hline & $\mathrm{R}^{2}$ & 0.9799 \\
\hline \multirow{3}{*}{ Temkin } & $\mathrm{B}_{1}$ & 5.24 \\
\hline & $\mathrm{K}_{\mathrm{T}}$ & 76.75 \\
\hline & $\mathrm{R}^{2}$ & 0.9676 \\
\hline
\end{tabular}
was a spontaneous process. The decrease in $\Delta \mathrm{G}^{\circ}$ with the increase of temperature indicates more efficient adsorption at higher temperature. The positive values of $\Delta \mathrm{H}^{\circ}$ confirm that the sorption of BBR onto MWCNTs is endothermic in nature. Figure 13 shows the Van't Hoff plot for the adsorption of BBR on MWCNTs.

Table 2: Isotherm parameters for BBR adsorption on MWCNTs.

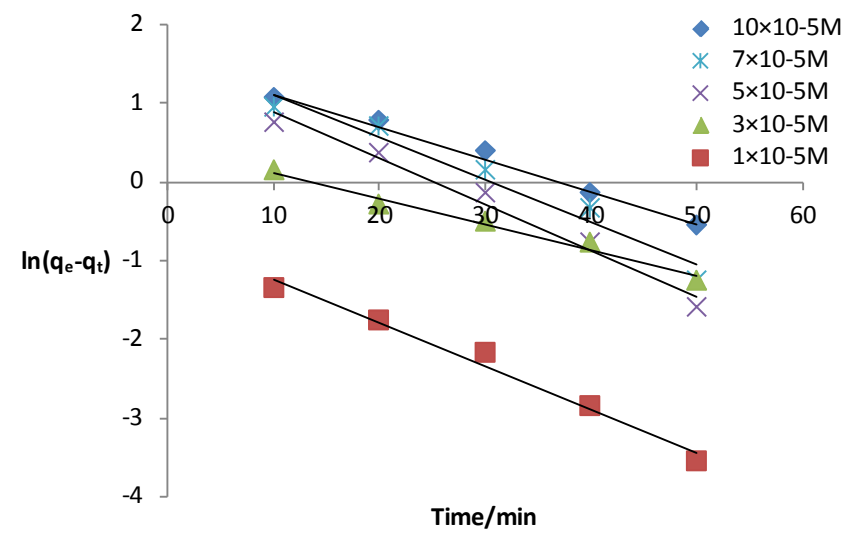

Figure 10: Pseudo-first order kinetic model for the adsorption of BBR on MWCNTs. 


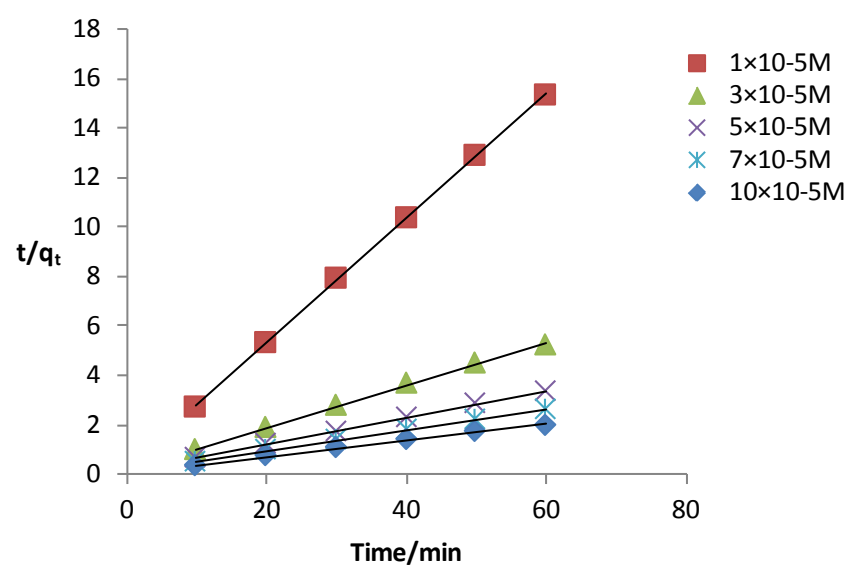

Figure 11: Pseudo-second order kinetic model for the adsorption of BBR on MWCNTs.

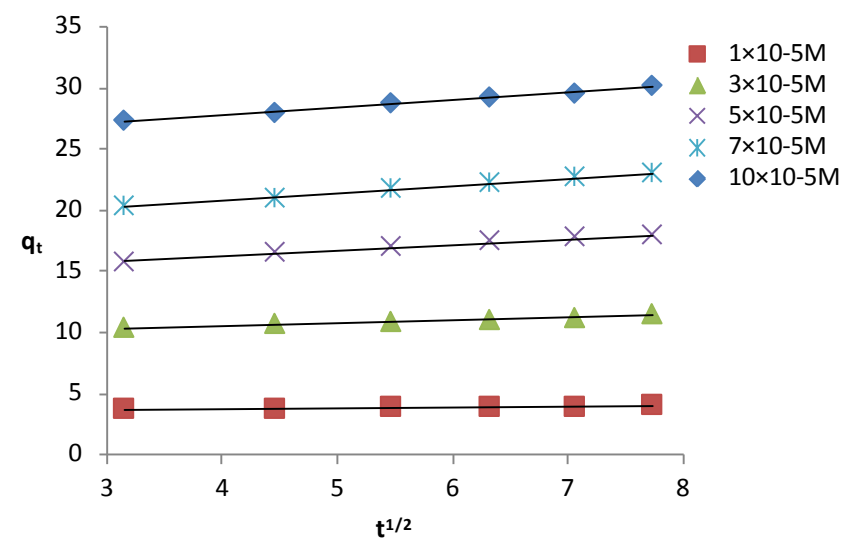

Figure 12: Intra particle diffusion model for the adsorption of BBR on MWCNTS.

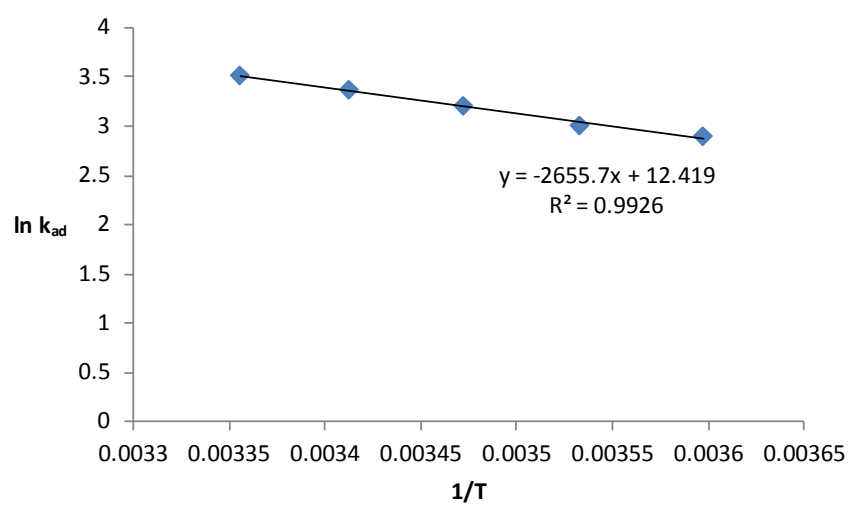

Figure 13: Plot of $\operatorname{lnK}$ versus $1 / T$ for estimation of thermodynamic parameters.

\section{Conclusions}

This study shows that MWCNT scan be used effectively for the removal of BBR from aqueous solution. $25 \mathrm{mg}$ is the optimum dosage of MWCNTs to adsorb BBR. The adsorption capacity of the BBR on MWCNTs increased with the increasing of initial concentration of

\begin{tabular}{|c|c|c|c|c|}
\hline \multirow{2}{*}{ Con./M } & \\
\hline & $\mathrm{q}_{\mathrm{e}, \mathrm{exp}}(\mathrm{mg} / \mathrm{g})$ & $\mathrm{q}_{\mathrm{e}, \mathrm{cal}}(\mathrm{mg} / \mathrm{g})$ & $\mathrm{k}_{1}\left(\mathrm{~min}^{-1}\right)$ & $\mathrm{R}^{2}$ \\
\hline $1 \times 10^{-5}$ & 3.91 & 0.4964 & -0.0549 & 0.9812 \\
\hline $3 \times 10^{-5}$ & 11.43 & 1.5357 & -0.0326 & 0.9826 \\
\hline $5 \times 10^{-5}$ & 17.87 & 4.3150 & -0.0586 & 0.9799 \\
\hline $7 \times 10^{-5}$ & 22.88 & 5.2446 & -0.0542 & 0.9595 \\
\hline $10 \times 10^{-5}$ & 30.06 & 4.6140 & -0.0414 & 0.9903 \\
\hline \multirow{2}{*}{ Con./M } & \multicolumn{4}{|c|}{ Pseudo second order model } \\
\hline & $\mathrm{q}_{\mathrm{e}, \mathrm{exp}}(\mathrm{mg} / \mathrm{g})$ & $\mathrm{q}_{\mathrm{e}, \mathrm{cal}}(\mathrm{mg} / \mathrm{g})$ & $\mathrm{K}_{2}(\mathrm{~g} / \mathrm{mg} \min )$ & $\mathrm{R}^{2}$ \\
\hline $1 \times 10^{-5}$ & 3.91 & 3.9761 & 0.8793 & 0.9999 \\
\hline $3 \times 10^{-5}$ & 11.43 & 11.6279 & 0.5584 & 0.9992 \\
\hline $5 \times 10^{-5}$ & 17.87 & 18.4162 & 0.4645 & 0.9997 \\
\hline $7 \times 10^{-5}$ & 22.88 & 23.5849 & 0.4525 & 09995 \\
\hline $10 \times 10^{-5}$ & 30.06 & 30.6748 & 0.5563 & 0.9995 \\
\hline \multirow{2}{*}{ Con./M } & \multicolumn{4}{|c|}{ Intra particle diffusion model } \\
\hline & $\mathrm{q}_{\mathrm{e}, \mathrm{exp}}(\mathrm{mg} / \mathrm{g})$ & $\mathrm{c}(\mathrm{mg} / \mathrm{g})$ & $\mathrm{K}_{3}\left(\mathrm{mg} / \mathrm{g} \mathrm{min}{ }^{1 / 2}\right)$ & $\mathrm{R}^{2}$ \\
\hline $1 \times 10^{-5}$ & 3.91 & 3.4893 & 0.0563 & 0.9921 \\
\hline $3 \times 10^{-5}$ & 11.43 & 9.6038 & 0.2268 & 0.9453 \\
\hline $5 \times 10^{-5}$ & 17.87 & 14.367 & 0.4674 & 0.9885 \\
\hline $7 \times 10^{-5}$ & 22.88 & 18.46 & 0.5817 & 0.9905 \\
\hline $10 \times 10^{-5}$ & 30.06 & 25.24 & 0.6161 & 0.9956 \\
\hline
\end{tabular}

Table 3: Adsorption parameters of BBR adsorption on MWCNTs.

\begin{tabular}{|c|c|c|c|c|c|c|c|}
\hline \multirow{2}{*}{ Con./M } & \multicolumn{5}{|c|}{$\Delta \mathbf{G}^{\circ} / \mathrm{k} \mathrm{J} \mathrm{mol}^{-1}$} & \multirow{2}{*}{$\Delta \mathrm{H}^{\circ} / \mathrm{k} \mathrm{J} \mathrm{mol}^{-1}$} & \multirow{2}{*}{$\Delta \mathrm{S}^{\circ} / \mathrm{J} \mathrm{mol}^{-1} \mathrm{~K}^{-1}$} \\
\hline & $5^{\circ} \mathrm{C}$ & $10^{\circ} \mathrm{C}$ & $15^{\circ} \mathrm{C}$ & $20^{\circ} \mathrm{C}$ & $25^{\circ} \mathrm{C}$ & & \\
\hline $5 \times 10^{-5}$ & -6.68 & -7.05 & -7.65 & -8.18 & -8.70 & 22.08 & 103.2 \\
\hline
\end{tabular}

Table 4: Thermodynamic parameters of adsorption BBR on MWCNTs.

BBR. The equilibrium adsorption capacity of BBR increased with temperature. The optimum contact time and $\mathrm{pH}$ were $10 \mathrm{~min}$ and 5 respectively. The adsorption kinetics was fitted by a pseudo-second order kinetic model. The adsorption of BBR on MWCNTs has been described by the Langmuir, Freundlich and Temkin adsorption isotherm models. The equilibrium data were fitted with the Freundlich isotherm. $\mathrm{R}_{\mathrm{L}}$ values for $\mathrm{BBR}$ adsorption onto MWCNTs indicate favorable adsorption. Adsorption of BBR was found to be spontaneous at the temperatures under investigation. The positive value of $\Delta H^{\circ}$ confirmed the sorption process was endothermic.

\section{References}

1. Hussein FH, Halbus AF (2012) Rapid decolorization of cobalamin. International Journal of Photoenergy 1-9.

2. Crini G (2006) Non-conventional low-cost adsorbents for dye removal: a review. Bioresour Technol 97: 1061-1085

3. Garg VK, Amita M, Kumar R, Gupta R (2004) Basic dye (methylene blue) removal from simulated wastewater by adsorption using Indian rosewood sawdust: a timber industry waste. Dyes Pigments 63: 243-250.

4. Hussein FH (2012) Photochemical treatments of textile industries wastewater. Asian Journal of Chemistry 24: 5427-5434.

5. Seshadri S, Bishop PI (1994) Anaerobic/aerobic treatment of selected azo dyes in wastewater. Waste Management 14: 127-137.

6. Hussein FH, Obies MH, Ali Drea AA (2010) Photodecolorization of Bismarck brown $\mathrm{R}$ in the presence of aqueous zinc oxide suspension. International journal of chemical sciences 8: 2763-2774.

7. Mitchell M, Ernst WR, Rasmussen ET, Bagherzadeh P, Lightsey GR (1978) Adsorption of textile dyes by activated carbon produced from agricultural, municipal and industrial wastes. Bull Environ Contam Toxicol 19: 307-311.

8. Garg VK, Gupta R, Bala Yadav A, Kumar R (2003) Dye removal from aqueous solution by adsorption on treated sawdust. Bioresour Technol 89: 121-124.

9. Aksu Z (2005) Application of biosorption for the removal of organic pollutants: a review. Process Biochem 40: 997-1026. 
10. Long RQ, Yang RT (2001) Carbon nanotubes as superior sorbent for dioxin removal. J Am Chem Soc 123: 2058-2059.

11. lijima S (1991) Helical microtubules of graphitic carbon. Nature 354: 56-58.

12. Yang R T (2003) Adsorbents: Fundamentals and applications. John Wiley and Sons, Inc.

13. Torres-Torres C, Peréa-López N, Martínez-Gutiérrez H, Trejo-Valdez $M$ Ortíz-López J, et al. (2013) Optoelectronic modulation by multi-wall carbon nanotubes. Nanotechnology 24: 045201

14. Aroua MK, Leong SP, Teo LY, Yin CY, Daud WM (2008) Real-time determination of kinetics of adsorption of lead(II) onto palm shell-based activated carbon using ion selective electrode. Bioresour Technol 99: 5786-5792.

15. Toor M, Jin B (2012) Adsorption characteristics, isotherm, kinetics, and diffusion of modified natural bentonite for removing diazo dye. Journal of Chemical Engineering 187: 79-88.

16. Jain M, Garg VK, Kadirvelu K (2010) Adsorption of hexavalent chromium from aqueous medium onto carbonaceous adsorbents prepared from waste biomass. J Environ Manage 91: 949-957.

17. Poinern GEJ, Parsonage D, Issa TB, Ghosh MK, Paling E, et al. (2010) Preparation, characterization and $\mathrm{As}(\mathrm{V})$ adsorption behaviour of CNTferrihydrite composites. International Journal of Engineering, Science and Technology 2: 13-24

18. Shahryari Z, Goharrizi AS, Azadi M (2010) Experimental study of methylene blue adsorption from aqueous solutions onto carbon nano tubes. International Journal of Water Resources and Environmental Engineering 2: 16-28.

19. Stafiej A, Pyrzynska K (2007) Adsorption of heavy metal ions with carbon nanotubes. Separation and Purification Technolog 58: 49-52.

20. Jain R, Shrivastava M (2008) Adsorptive studies of hazardous dye Tropaeoline 000 from an aqueous phase on to coconut-husk. J Hazard Mater 158: 549-556.

21. Shirmardi M, Mesdaghinia AR, Mahvi AH, NasseriS, Nabizadeh R (2012) Kinetic and equilibrium studies on adsorption of acid red 18 (Azo-Dye) using multiwall carbon nanotubes (MWCNTs) from aqueous solution. E-Journal of Chemistry 9: 2371-2383.

22. Bazrafshan E, Mostafapour FK, Hosseini AR, Khorshid AR, Mahvi AH (2013) Decolorisation of reactive red 120 dye by using single-walled carbon nanotubes in aqueous solution. Journal of Chemistry 2013: 1-8.
23. Al-Degs YS, El-Barghouthi MI, El-Sheikh AH, Walker GM (2008) Effect of solution $\mathrm{pH}$, ionic strength, and temperature on adsorption behavior of reactive dyes on activated carbon. Dyes and Pigments 77: 16-23.

24. Kumar KV, Sivanesan S (2006) Isotherm parameters for basic dyes onto activated carbon: comparison of linear and non-linear method. J Hazard Mater 129: $147-150$.

25. Langmuir I (1918) The adsorption of gases on plane surfaces of glass, mica and platinum. The Journal of the American Chemical Society 40: 1361-1403.

26. Webi TW, Chakravorti RK (1974) Pore and solid diffusion models for fixed-bed adsorbers. Al Ch E Journal 20: 228-238.

27. Hamdaoui $O$ (2006) Batch study of liquid-phase adsorption of methylene blue using cedar sawdust and crushed brick. J Hazard Mater 135: 264-273.

28. Wang S, Boyjoo Y, Choueib A (2005) A comparative study of dye removal using fly ash treated by different methods. Chemosphere 60: 1401-1407.

29. Freundlich $H$ (1985) Uber die adsorption in lunsungen. Journal of Physical Chemistry 57: 387-470.

30. Temkin M, Pyzhev V (1940) Kinetics of the synthesis of ammonia on promoted iron catalysts. J Phys Chem 13: 851-867.

31. Hussein FH, Halbus AF, Abdalrazak FH, Athab ZH (2013) Adsorption of cobalamin onto synthesized carbon nanotubes (CNT). Journal of Applicable Chemistry 2: 589-604.

32. Halbus AF, Athab ZH, Hussein FH (2013) Adsorption of Disperse Blue Dye on Iraqi Date Palm Seeds Activated Carbon. International journal of chemical sciences 11: 1219-1233

33. Karagöz S, Tay T, Ucar S, Erdem M (2008) Activated carbons from waste biomass by sulfuric acid activation and their use on methylene blue adsorption. Bioresour Technol 99: 6214-6222.

34. Khan SA, Rehman R, Khan MA (1995) Adsorption of Cr (III), Cr (VI) and Ag (I) on Bentonite. Waste Management 15: 71-82.

35. Chen PH, Zhou XZ, LiY X, Li DP, LiJ, et al. (2014) Kinetic and thermodynamic study adsorbing methylene blue on nanozirconia. Applied Mechanics and Materials 475-476: 1311-1319.

36. Gao L, Gao H (2014) Haematoxyl in sorption onto yak hair: kinetic and thermodynamic studies. Coloration Technology 130: 21-26.

37. Nugent $P$, Belmabkhout $Y$, Burd SD, Cairns AJ, Luebke R, et al. (2013) Porous materials with optimal adsorption thermodynamics and kinetics for $\mathrm{CO} 2$ separation. Nature 495: 80-84. 